\title{
Women in STEM Networks: Who Seeks Advice and Support from Women Scientists?
}

\author{
Mary K. Feeney* \\ Assistant Professor \\ Department of Public Administration \\ University of Illinois at Chicago \\ 412 S. Peoria St. M/C 278 \\ Chicago, IL. 60607 \\ mkfeeney@uic.edu \\ 312-355-4734

\section{Margarita Bernal \\ Research Associate \\ Department of Public Administration \\ University of Illinois at Chicago}

\begin{abstract}
Supporting and advancing women's science careers continues to be of interest to researchers, scientists, science funders, and universities. Similarly, professional advice and support networks are important to understanding the advancement of scientific careers. This research aims to marry these two lines of research to investigate and compare the ways in which men and women scientists seek advice and support from women in their networks. Using a sample of academic scientists in non-medical biology, chemistry, computer science, earth and atmospheric sciences, electrical engineering, and physics we assess the extent to which women and men scientists seek advice and support from women in their networks. We find that field of science is the primary predictor for the presence of women in scientists' advice and support networks. We also find that citizenship, rank, age, and friendship are significantly related to the proportion of women in women's networks, but are not related to the proportion of women in men's networks. We conclude with a discussion of the findings and the distinctions between men and women scientists' advice and support networks.
\end{abstract}

Keywords: women, networks, advice, support, field of science

*Corresponding Author 


\section{Women in STEM Networks: Who Seeks Advice and Support from Women Scientists?}

\section{Introduction}

For over forty years now, researchers have sought to understand what explains the lack of women in science, technology, engineering, and mathematics. Theories abound as to why women are underrepresented in the sciences. From the 2005 statements of Lawrence Summers, then President of Harvard University, that there are innate biological differences between men and women which may explain why fewer women succeed in academic science and math careers to research on the ways in which the structure of science careers are not conducive to women who wish to balance work and family (Browne 2004), there is much debate on the reasons for the dearth of women in science and how to attract and retain women in these careers.

In addition to, and sometimes as a result of this research, the federal government, universities, and professional associations have made numerous efforts to nurture and support women scientists. For example, the NSF-funded ADVANCE Institutional Transformation Program aims to "develop systemic approaches to increase the representation and advancement of women in academic science, technology, engineering and mathematics (STEM) careers, thereby contributing to the development of a more diverse science and engineering workforce” (NSF 2009). Meanwhile, professional associations work to connect women members to federal programs supporting women scientists, connect women scientists to one another, and create a venue for discussing and addressing work and life issues particular to women scientists. And universities have created programs to support and advance women undergraduates, graduate students, postdoctoral researchers, and faculty. In summary, there is an abundance of research and practical efforts aiming to develop a sex balance in STEM fields and improve the status of women scientists.

Researchers argue that the dearth of women in science is related to a complex interaction of a number of factors such as career choice, socialization systems, department climate, barriers to family and work balance, and an education system that may disadvantage and discourage women students who are interested in science (Callister 2006; Etzkowitz and Kemelgor 2001; Kemelgor and Etzkowitz 2001; Long 1992; NAS 2003; NSF 2004; National Research Council 2001; Rapoport et al. 2002). While important efforts have been made to attract and retain women studying in STEM fields, the challenge remains in retaining women PhDs in academic science careers. Efforts to increase the number of women in the 
pipeline and repair or prevent leaks in the pipeline are important mechanisms for nurturing women scientists. However, researchers are becoming increasingly aware that the pipeline repairs are necessary, but not sufficient (Kulis et al. 2002). Instead, women need better informal networks throughout their training and careers to ensure their success as scientists.

This research takes a first step at understanding the presence of women in informal science networks by investigating the presence of women in men and women scientists' advice and support networks. This research asks the following research questions: Do men and women scientists differently report the presence of women in their advice and support networks? And if so, what are some of the determinants of having women in a scientist's advice and support network? For example, is the presence of women in advice and support networks related to field of science and a critical mass of women in that field? Is the presence of women in a scientist's informal network related to the scientist's sex, age, or some other demographic characteristic, such as citizenship, marital status, or the presence of children? This research is important for two reasons. First, while there is an abundance of research investigating collaboration through co-authorships, there is little large-scale empirical research on the informal networks of scientists. Second, rather than focusing solely on women scientists, we use a sample of both men and women scientists in six fields (non-medical biology, chemistry, computer science, earth and atmospheric sciences, electrical engineering, and physics) to investigate the presence of women in informal networks.

This research uses data from a national survey of scientists (NETWISE) to understand the prevalence of women in women and men's informal advice and support networks. We begin with a discussion of the literature on women in science. From this literature we develop hypotheses about the structure of men and women scientists’ professional and collegial advice and support networks.

\section{Networks in Science}

In academic science, advice and support networks are critical to the training of undergraduate students, graduate students, postdoctoral research, and faculty. Professional networks are formed in the early stages of science careers in cohorts of students. For example, lab partners, study groups, and students preparing for qualifying exams often rely on one another to learn, reinforce knowledge, and pick up the skills and training needed to succeed. Role models, in the form of advisers and mentors, guide student scientists through an apprenticeship that involves both training and socialization. Thus, informal social and 
professional networks in science are critical for the transmission of information, the exchange of ideas and resources, the validation of research, and the encouragement critical to success.

Once a scientist earns the $\mathrm{PhD}$, networks remain important for job placement and advancement. Etzkowitz and colleagues (2000) describe the science network as a 'Kula Ring' where informal organizing and information sharing ensures that leaders of the groups transmit information to new comers and the community by distributing resources, information, and power. Because scientists exchange ideas, resources, information, and support and reinforce one another's work in these informal communities, social networks and connections are critical to the structure and advancement of science careers (Tierney and Benismon 1996; Tierney and Rhoads 1993). Because networks and socialization are critical to the training and professional development of scientists, they become even more important for women scientists who are in the minority in most fields of science. Researchers argue that less visible social cues, negative interactions, and lack of access to important networks create structural impediments to women's careers and accumulate over the course of women's careers (Merton 1973; Settles et al. 2007; Zuckerman 1989) resulting in frustration and withdrawal.

The structure of networks in science communities can result in professional advancement and the transmission of tacit knowledge (Epstein 1970) or the isolation of a scientist (Emmett 1992). Research overwhelmingly points to the importance of formal and informal networks for both men and women scientists, and is hypothesized to be an important link to the advancement of women in science. While it is important to increase the number of women pursuing science training (Curtin et al. 1997; National Academies of Science 2003; Seymour 1995) and the placement of women scientists in academic departments (Toren and Kraus 1987; Valian 2005), integrating women into informal science networks, at all levels, will undoubtedly improve the ways in which women scientists persist.

\section{Women's Networks in Science}

"My science is different because of my socialization, not because of my gender" (Etzkowitz et al. 2000, pg 92)

There is growing evidence that one of the most important barriers to women in science is a work structure and professional socialization system that presents women with two choices: (1) pursue the "male” model of science or (2) drop out of the academic track. Research suggests that socialization barriers 
serve to isolate women scientists and lower their support, confidence, perseverance, aspirations, and success (Acker 1990; Etzkowitz et al. 1994; Kanter 1977; Kemelgor and Etzkowitz 2001). If we accept that informal networks and support are critical to the success of modern scientists, this isolation can put women at a severe deficit compared to their men peers (Kemelgor and Etzkowitz 2001).

Women scientists often report being “more isolated” in their training and careers, with a lack of direction and professional contacts to advance their careers. These feelings of isolation can become more intense as women scientists move, into departments, labs, and senior ranks where women make up even smaller proportions of the community. Isolation of scientists can result in significant barriers to scientific discovery and ultimately the withdrawal of a scientist from academic research (Kemelgor and Etzkowitz 2001; Merton 1968; Lin et al. 1981). Isolated scientists can be less motivated and have lower aspirations than their peers, which in turn can affect their work outcomes (Fox-Keller 1985; Horning 1993).

Etzkowitz and colleagues (2000) note that access points to informal networks can occur at multiple times in a scientist's career, but that on average women scientists consistently lack access to informal networks leaving them at a severe disadvantage as compared to their men peers. Women who earn a $\mathrm{PhD}$ in the sciences and a position in a top research department report less dense and fewer connections to the academic system and “[w]omen’s networks tend to be poorer in social capital than those of their male peers” (Etzkowitz et al. 2000, pg 171). Informal networks can be particularly important in academic science careers as individual scientists negotiate salaries, build strategies to advance their careers, and navigate the academic career system. Thus, earning a degree is not the same as developing the social and professional networks needed to successfully pursue an academic science career.

Recognizing that both men and women colleagues can play an important role in advancing the careers of women scientists (Etzkowitz et al. 2000), rather than investigate the structure of women’s networks and men's networks as a way of determining if women and men are connected to the "right people”, we are interested in understanding how well women have penetrated the informal networks of all scientists (men and women). Thus, we investigate the presence and proportion of women in advice and support networks. Given the historic under-representation of women in science, the continued treatment of women scientists as “token” members of some departments, and efforts to support and better connect 
women to other women scientists, we expect that women scientists as compared to men scientists will report having a higher number of women in their advice and support networks.

Hypothesis 1: As compared to men scientists, women scientists will report a higher proportion of women in their advice and support networks.

While we expect that women will be present in men and women scientists’ networks at different rates, because women remain a minority in most STEM fields we also expect that scientists will call on women colleagues for different types of advice. First, women may seek out the advice of other women when faced with a woman specific issue. Likewise men scientists may seek out a woman scientist for advice related to issues either she is familiar with or which he perceives as being more important to women - such as advice about family and life balance. While scientists seeking to balance work and family life are not necessarily women scientists, we expect that a young man scientist with children and a balanced family life (shared household duties with the spouse) will be more likely to see advice about work / family balance from a woman scientist.

Just as scientists may turn to women scientists for advice on work and family balance, we expect that scientists are less likely to turn to women scientists for advice on publishing and grant getting. While it is certainly not true that men are better at getting grants and publishing, it is true that in general the successful prolific scientists in the department are more likely to be men - simply because men make up a larger proportion of scientists and an even larger proportion of senior scientists. For example, women make up a mere $6 \%$ of full professors in top physical science departments, around $5 \%$ in mathematics, and less than $4 \%$ of the full professorships in electrical, civil, and mechanical engineering departments (Handelsman et al. 2005: 1190). Because of the traditional dominance of men in these fields, we expect that the senior, influential, potential advice givers on topics of publishing and grant getting in most scientists' lives will be men.

Hypothesis 2: Women and men scientists will seek different types of advice from women in their advice networks.

Hypothesis 3: Women and men scientists will seek different types of support from women in their support networks.

\section{Field of Science}


Any study aimed at understanding the presence of women in scientists' informal advice and support networks must account for the field of science. Although women are the minority in most science fields, the size of that minority is important to understanding the progress women have made in the field, the amount of support they have from one another, and their ability to reach a critical mass to address issues particular to their group. Additionally, the number of women in the field will help to explain the likelihood that men and women scientists will report having women in their advice and support networks. Clearly, scientists working in a field with few women scientists will be less likely to have women in the network, as compared to those in a field with a high number of women scientists.

Researchers have tried to understand the ways in which the presence of women in an academic department may exacerbate or alleviate the barriers to women's careers. Research indicates that women suffer when they represent a stark minority, and that small increases in the size of that minority can have large outcomes for women. Kanter (1977) proposes a model in which small minorities, less than $15 \%$, face extensive discrimination, isolation, and tokenism. In the case of academic scientists, the "token" woman in the department may be expected to serve on more than an average number of committees, mentor a higher proportion of students (in particular women students), and take on roles that are not conducive to competing with the men. In sum, when minority scientists are viewed as "tokens" they run the risk of taking on responsibilities that overburden already disadvantaged scientists.

Kanter (1977) argues that empowerment and advancement requires a "critical minority” of at least $15 \%$. Critical minorities constitute a group large enough to organize and work with the majority or take up cases to advance their interests with larger minorities (e.g. 35\%) tilting power to their advantage. Researchers argue that when a minority group achieves "critical mass" the group is better situated to protect minority interests and legitimize different ways of doing science (Oliver and Marwell 1988; Kanter 1977). Similarly, researchers note that the more women that enter the program or field, the more likely they are to increase their share of resources and achievement levels (Gutek 1985; Konrad 1986).

Still, some evidence points to an inverse relationship between women's minority size and academic success, noting that a larger proportion of women does not necessarily reduce the negative treatment of women or negative perceptions of gender-attributes and science (Acker 1990; Settles et al. 2007; Toren and Kraus 1987). It remains possible that as women increase their representation in a field or a 
department they create a separate class of researchers that rely on one another, but remain isolated from the majority population of men scientists (Kanter 1977; South et al. 1992). Divisions by rank, subfield, lab, or research group could exacerbate feelings of isolation and separateness (Kanter 1977) or could signify homophily, or strategies and preferences to work with similar people (McPherson, et al. 2001; Pepe and Rodriguez 2009; Rodriguez and Pepe 2008). Research indicates that although growth in the proportion of women in fields is important for creating an environment of support and power for women, it is not a sufficient tool for improving women’s access to professional, social, formal, and informal networks. While there is "support and safety in numbers" (Etzkowitz 2000: 111), support and safety without integration can result in the continued isolation of women scientists (Kemelgor and Etzkowitz 2001).

We propose that field of science will remain important to understanding the presence of women in the advice and support networks of both men and women scientists. Since women make up a larger proportion of biological fields - biology and also the biological subfields of chemistry, engineering, mathematics, and physics - we expect that their presence will increase the likelihood that both men and women scientists will report having women in their advice and support networks. Likewise, with women making up a mere 16\% of those earning doctorates in physics in 2006 (SED 2006), we expect that women will make up a small to negligible proportion of networks of men and women physicists.

Hypothesis 4: Scientists' patterns for advice seeking and support from women colleagues will significantly vary by field.

\section{Data and Models}

This research uses data from the National Science Foundation (NSF) funded study "Women in Science and Engineering: Network Access, Participation, and Career Outcomes” (NETWISE 2006), a study of women and men's access to professional networks and career outcomes. We begin with a description of the NETWISE data. Next, we discuss the patterns of women's networks in six fields of sciences. Third, we test hypotheses about variation in women’s advice and support networks. We conclude with a discussion of the results.

The NETWISE data come from a national survey of scientists and engineers at 151 Carnegiedesignated Research I universities (as identified in 2005) from six disciplines: non-medical biology, chemistry, computer science, earth and atmospheric sciences, electrical engineering, and physics. The survey collected data on the social and collaborative networks from a random sample of 3,677, stratified by 
sex, rank, and discipline (the population was approximately 25,000 scientists and engineers). Sample weights were calculated using the inverse of the probability of selection and employed in calculating all results presented below.

The survey was administered online and closed in early 2007. Overall, 1,628 completed surveys were returned for a $50.1 \%$ response rate and a usable response rate of $47 \% .{ }^{1}$ We use two types of data for this research: (1) the respondent (egos) data, which contain detailed personal information about the respondent, and (2) the respondents' network data (the alters), which contain information about members of the respondents' network. The latter includes demographic information about the alters and information about the type of interactions between alters and respondents, as reported by the respondents. For this analysis, we removed 27 emeritus and research scientists and 107 who did not report information about their networks, leaving a sample of 1494 . The egos reported information on a total of 12,727 alters in their respective networks. We removed 90 alters because the ego did not report the alter's sex. We aggregated the network information for the 12,637 alters, by respondent.

Network Data. The NETWISE survey asked each respondent to provide information about the professional, advice, support, and mentoring networks. The respondent was asked to identify up to five individuals you regularly talk with about research; up to five individuals from whom you seek advice about your career or professional development; up to five individuals with whom you regularly talk about important university or department related issues; and one primary mentor. These questions resulted in a set of up to 16 names generated for each respondent's professional advice and support network. ${ }^{2}$ After the respondent provided names of people in her network, those names were then inputted into a series of questions about the network. For example, the respondent was asked the sex of each person in her network and how long she has known the alter. This study uses the respondent as the unit of analysis and assesses the general patterns and density of women in respondent networks. We collapse the alter measures to note

\footnotetext{
${ }^{1}$ Non-responses due to bad addresses were removed for the calculation of response rate.

2 Exact question wording: Q1. Over the past two academic years, which individuals at your university have been your closest research collaborators? Collaboration includes proposal generation, working on a research project, writing/presenting an academic paper/book or book chapter, or developing industrial products or patents.) Q2. Over the past two academic years, who have been your closest research collaborators outside of your institution (including other academic institutions, government and industry?) Q3. With which individuals do you regularly talk with about research but have never formally collaborated? Q4. From whom do you seek advice about your career or professional development? Q5. With whom do you regularly talk about important university or department related issues?
} 
the overall distribution of women in the respondent's (ego’s) network. For example, the variable, Women in Network, indicates the proportion of the respondent's (ego's) network that is comprised of women calculated as the sum of women in the network divided by the total number of individuals in the network.

Dependent Variables. The hypotheses are tested using 11 dependent variables derived from eight survey items that asked respondents about their advice and support networks. The dependent variables note the sex composition of each respondent's network. The dependent variables for seeking advice for Publishing, Grant Getting, Overall Career Development, Collegial Interactions, and Work/family Balance are derived from the following NETWISE survey item:

\begin{tabular}{c|c|c|c|c|c}
\hline \multicolumn{6}{c}{ Q. What advice do you typically seek from the following individuals? (Check all that apply) } \\
\hline Advice about: & Publishing & Grant getting & $\begin{array}{c}\text { Overall career } \\
\text { development } \\
\text { strategies }\end{array}$ & $\begin{array}{c}\text { Interactions } \\
\text { with colleagues }\end{array}$ & $\begin{array}{c}\text { Work/family } \\
\text { balance }\end{array}$ \\
\hline Name 1 & & & & & \\
\hline Name 2 & & & & & \\
\hline
\end{tabular}

We then calculated the number of people in the network from which the respondent seeks publishing advice and the proportion of those individuals that are women. We then calculated the proportion of women from which the respondent reported seeking each type of advice. For example, Publishing Advice is the number of women from which the respondent seeks publishing advice, divided by the total number of individuals from which the respondent seeks publishing advice. Grant Advice indicates the proportion of women in the respondent's grant advice network; Career Advice is the proportion of women in the career development advice network; Colleague Advice is the proportion of women within the network providing advice about interactions with colleagues; and Work/Family Advice is the proportion of women in the total network of individuals from which the respondent seeks advice about work/family balance. Finally, we include a variable that is the sum of the aforementioned advice network variables. Total Advice is the proportion of women in the respondent's advice network.

The three dependent variables for receiving support are Review Papers, Introductions, and Nominations. The support variables are derived from the following NETWISE survey item: Colleagues often support each other in aspects of career development. Please indicate if the people you named have: (1) Reviewed your papers or proposals prior to submission (on which they were not a co-author); (2) 
Introduced you to potential collaborators outside of your university; and (3) Nominated you for an award or as an invited speaker.

The three variables measuring the proportion of women providing support to the respondent are calculated in the same manner as the advice variables: Review (Total Women Review / Total Review); Introduce (Total Women Introduce / Total Introduce); and Nominate (Total Women Nominate / Total Nominate). Total Support is the proportion of women in the respondent's support network.

Independent Variables. Because the unit of analysis is the respondent's network, we include a number of independent variables about the respondent. The respondent's sex is measured by the variable Women (=1). Three dummy variables indicate the respondent's academic position: Assistant Professor, Associate Professor, or Full Professor. The respondent's field is noted with the following mutually exclusive variables: Biology, Chemistry, Computer Sciences, Earth and Atmospheric Sciences, Electrical Engineering, and Physics.

We control for respondent's age with two variables: Age and Age Squared. We also control for Time since PhD and if the respondent is Tenured (=1). These measures, while correlated with age and rank, enable us to control for young high ranked faculty or faculty who have entered academia after spending time in another career. Four binary variables serve as controls for race, citizenship, marital status, and having dependent children. White, is coded one if the respondent self-reported her race as white ( $0=$ nonwhite). Citizen is coded one if the respondent is a US citizen ( $0=$ not a US citizen). We control for race and citizenship, because research indicates that scientists from ethnic and racial minority groups and non-US citizens may have different barriers to socialization and professional networking (Kulis et al. 1999; Lee 2004; Sabharwal 2008).

Research indicates that marital status is especially important if an academic scientist's location is geographically constricted by the spouse’s career options (Rosenfeld 1984; Kulis and Sicotte 2002) and that men scientists perceive marriage and children as impediments to women scientist's careers (Etzkowitz et al. 2000, pg. 134), so we include the variable, Married (=1). We control for the presence of dependent children in the respondent's household: Dependent Children (1= at least one dependent child in the respondent's household). Married with kids is an interaction variable. 
Finally, we include the variable, Friendship, which indicates the proportion of the respondent's network that is composed of close friends. For each network contact that the respondent reported (16 possible) we asked if this person is a close friend. This variable indicates the density of the respondent's networks and the extent to which the respondent relies on friendship as a component of advice and support networks. Because research indicates that women are more likely to have and rely upon colleagues with whom they have social and emotional bonds and that this collaborative and relational approach to science and the workplace is particularly important for the new generation of scientists (Etzkowitz et al. 2000, pg 151), we expect that friendship will play an important role in women's professional advice and support networks. Summary statistics for all variables are listed in table 1 and correlations in Appendix 1.

\section{Analysis and Results}

We present the analysis and results in two sections. First, we begin with a description of the distribution of women in scientists' advice and support networks, by field. Second, we present results from a set of models predicting (1) the proportion of women in advice and support networks and (2) models predicting the proportion of women based on five types of advice and three types of support.

Women in Scientists' Networks, by Field. The following tables present the patterns of scientists' networks in six fields of sciences: non-medical biology, chemistry, computer science (CS), electrical engineering (EE), earth and atmospheric sciences (EAS), and physics. We begin with a discussion of the presence of women in advice and support networks, by sex, field, and academic position. Second, we highlight the ways in which women are present in different types of advice and support networks, followed by a discussion of variation in the types of advice and support sought from women, by field.

Table 2 shows the participation of women in the respondent's network, by field, academic position, and respondent sex. Of all the respondents in the sample, 58\% have at least one woman in their advice or support network. In general, there are more women than men respondents with women in their networks (78\% and 57\% respectively). Among STEM fields, earth and atmospheric scientists report the highest proportion of women in their networks, with nearly three quarters of EAS respondents reporting having at least one woman in their networks (89\% for women and $69 \%$ for men). In comparison, $70 \%$ of women in electrical engineering report having a woman in their networks and only $41 \%$ of men physicists report having a woman in their network. In summary, across all fields, women more than men report 
having at least one woman in their network and, on average, at least half of men computer scientists, electrical engineers, and physicists report not having a single woman in their networks.

[Insert table 2 about here]

When we look at the presence of women in scientists' networks, by rank, we find an interesting trend. Among men scientists, we see that $60 \%$ of men associate professors report having a woman in their network while just over half of men assistant and full professors (53\%) report having at least one woman in their advice and support networks. It is interesting to note that $45 \%$ of the men assistant professors in this representative sample report having not a single woman in their networks, though women scientists are more likely to be junior.

[Table 2 about here]

In addition to differences in the presence of women in networks, by field, there are differences in the presence of women in different types of advice and support networks. Table 3 shows the average percent of women within respondents' networks by type of advice and support. On average, respondents report that women make up around one tenth of their advice networks (13\%) and support networks (10\%). As expected, the type of advice most sought from women in science networks is advice about work/family balance. In fact, scientists report nearly double the proportion of women in work/family balance advice networks as compared to other types of advice networks such as publishing and grant getting advice where women make up $13 \%$.

[Table 3 about here]

When we disaggregate the advice and support networks by respondent sex, we see a stark difference in the average percent of women in women's networks as compared to men. In nearly all types of advice and support networks, women scientists report that women make up at least one fifth of their networks. In comparison, men report that women make up about 10\% of their advice and support networks. Women scientists seek more work/family balance advice (46\%) than publishing advice (23\%) from women scientists. Men show the same pattern as women, turning to women in their networks for advice about work/family balance (16\% for work/family balance and $11 \%$ for publishing). Men, on average, report having a larger proportion of women in their advice networks than in support networks. While this difference is not large, men report more women in their networks when seeking advice about grant getting, 
publishing, and career development than when seeking support by reviewing papers and introducing them to other scientists - both key components of informal networks.

The most common type of support from women is reviewing papers or proposals. Men report that women on average make up 7\% of their support network, with 9\% of their support network for reviewing papers or proposals being women. Women scientists report that, on average, more than one quarter of the people in their networks that have nominated them for an award are women. Overall, women scientists are more likely than men scientists to have women in their advice and support networks, regardless of the type of advice sought and support received. Moreover, both men and women biologists report the highest average number of women in their networks while physicists and electrical engineers report the lowest number of women in their networks, on average.

\section{Model Results}

In this section, we present the results from the models predicting the proportion of women in scientists' advice and support networks and (table 4) the models predicting the proportion of women in the five types of advice (tables 5A and 5B) and three types of support (table 6) networks. Rather than control for sex with a single independent variable and because using a single control for sex would capture all the variance between men and women in the intercept we present separate models for women and men. Splitting the sample allows each independent variable and the outcomes to vary by sex and can provide significantly different beta estimates on the independent variables, giving a more detailed understanding of how the relationships between all of the variables differ by sex.

[Table 4 about here]

Table 4 presents the results from the models predicting the proportion of women in scientists' networks, advice networks, and support networks, by sex. The presence and proportion of women in scientists' advice and support networks vary significantly by sex and field. Overall, women are significantly more likely to report having women in their networks. Table 4 shows that women compared to men, report $12 \%$ more women in their networks, with $15 \%$ more women in advice networks and $18 \%$ more in support networks.

When we consider women alone, we see that in general women in physics, chemistry, computer science (CS), EAS, and electrical engineering (EE) have significantly fewer women in their overall advice 
and support networks as compared to women in non-medical biology (the reference category). In comparison, men in physics, chemistry, and EE as compared to men in biology, have significantly fewer women in their networks, while there are little to no significant differences in the number of women in men's advice and support networks in CS and EAS. Women in physics and EE are the least likely to have women in their networks, as compared to women in the four other fields of science.

When we consider rank, we see that women associate professors, as compared to full professors, report significantly more women in their advice networks. Interestingly, there are not significant differences between the proportion of women in the support and advice networks of women assistant and full professors. For men associate professors, there are no significant differenced in the number of women in their advice and support networks.

For women, age, time since $\mathrm{PhD}$, and being white are not significantly related to the proportion of women in advice and support networks. Additionally, marital and parental status are not significantly related to women being present in women scientists' networks. For men scientists, time since $\mathrm{PhD}$ and being white are positively related to having women in advice and support networks, while being married and having kids are negatively related to the presence of women in their advice and support networks. U.S. citizens, as compared to non-citizens, are significantly more likely to report having a higher proportion of women in their advice and support networks. Being a U.S. citizen is associated with, on average, a 3\% increase in the proportion of women in scientists' advice and support networks a. The relationship between citizenship and having women in advice and support networks is much stronger for women than men. For men, US citizenship is related to a $1.5 \%$ increase in the proportion of women in the advice networks. For women, US citizens report a $10 \%$ increase in the proportion of women in the advice networks and an $11 \%$ increase in the proportion of women in the support networks, as compared to women non-citizens.

Finally, an increase in the proportion of people in the network that scientists' consider "close friends" is significantly and positively related to the proportion of women in the respondent's advice and support network. Respondents, on average, who have more friends in their networks report about $7.4 \%$ more women in their networks than those who have few to no friends in their networks. An increase in the number of friends in a woman scientist's network is related to an increase of $24 \%$ and $22 \%$ women in the advice and support network, respectively. In comparison, an increase of friends in men scientist's advice 
and support network is related to reporting $46 \%$ more women in the overall network. For men, being close friends with the people in the network is not significantly related to the number of women in the support network, but is positively related to the proportion of women in the advice network.

[Table 5A and 5B about here]

Advice Networks. The second analysis focuses on investigating variance in the types of advice sought from women scientists. Table 5A shows the results from the five regression analyses investigating men scientists reporting women in their networks providing advice on grant getting, career development, publishing, interactions with colleagues, and work/faculty balance. Table 5B shows the results from the same regression analyses for women scientists’ advice networks.

Table 5A indicates that for men scientists, rank is a significant indicator of having women in the advice network. Compared to full professors, assistant and associate professors are significantly less likely to seek publishing advice from women. Assistant professors are significantly more likely than full processors to seek career and colleague advice from women. Field of science is a consistent predictor of men having women in their advice networks. For example, physicists compared to biologists report significantly fewer women in their networks providing advice all types of advice. Chemists, on average, report $11 \%$ fewer women in their career advice networks than biologists. Interestingly, compared to biologists, electrical engineers and earth and atmospheric scientists report $4 \%$ and $14 \%$ more women in their work and family balance advice networks, respectively. Finally, while men scientists who are married report significantly fewer women in their networks (10\%) providing publishing, career, and colleague advice, other demographic variables such as time since $\mathrm{PhD}$, age, race, citizenship, and having children are not consistently related to the number of women to which men scientists turn to for advice.

Table 5B shows the results of the models predicting the proportion of women in women scientists' advice networks which, as indicated by the adjusted $\mathrm{R}^{2}$, explain between $5.2 \%$ and $12.2 \%$ of the variance in the proportion of women in advice networks. Similar to men, women physicists consistently report a lower proportion of women in their advice networks, as compared to biologists. Women physicists report 23\% fewer women in their career advice networks compared to biologists. Compared to women biologists, women chemists report $13 \%$ and electrical engineers report 22\% fewer women in their publishing advice networks, and computer scientists report 22\% fewer women in their work/family advice networks. In sum, 
women biologists consistently report significantly higher numbers of women in all of their advice networks, which may be the results of a critical mass of women in that field.

Overall, rank is not a significant predictor of women scientists having women in their advice networks. Women associate professors, as compared to full professors, report $10 \%$ more women in their publishing advice networks. We do not know if these women advice givers are senior, junior, or peers to the associate professors. Interestingly, age is positively related to having women in the grant advice network. A one-year increase in age is related to a 3\% increase in the proportion of women in the grant advice network. Finally, reporting an increase in the number of friends in the advice network is also positively related to having more women in the grant advice network. Thus women scientists appear to turn to "friends" for advice about grant getting, careers, and colleagues.

When we look at age, race, and family structure, we find no consistent significant relationships between these demographic measures and the proportion of women in women's advice networks. Citizenship, which is a significant predictor of men having women in career and work/family balance advice networks, is a significant predictor of women scientists having women in the advice network. Women scientists who are US citizens report significantly higher proportions of women providing advice about grant getting (10\%), careers (10\%), colleagues (15\%), and work family advice networks (19\%). One explanation for this relationship is that women scientists who are not US citizens face additional barriers in the work place. It is also possible that women US citizens are more likely to be integrated in professional societies and better able to develop advice networks with other women.

[Table 6 about here]

Support Networks. Table 6 shows the results from the models predicting the proportion of women in scientists' support networks. The adjusted $\mathrm{R}^{2}$ ranges from $7.6 \%$ to $8.3 \%$ for the sample of men. Physicists, as compared to biologists, report having fewer women in their networks providing support by reviewing papers and proposals (12\%), introducing them to potential collaborators (8\%), and nominating them for awards or as an invited speaker (6\%). In comparison to biologists, men in EAS are significantly more likely to report having women introduce them to potential collaborators (5\%) and nominate them for awards or as an invited speaker (10\%). For men, an increase in the time sing the $\mathrm{PhD}$ was awarded is 
consistently, significantly related to reporting a higher proportion of women in the support network, while men with dependent children as less likely to report having women in their support networks.

The models for the women sample explain between $6.4 \%$ and $17.9 \%$ of the variation in the proportion of women in their support networks. Similar to advice networks, field of science plays an important, significant role in predicting women in support networks. Compared to women biologists, women physicists report $27 \%$ fewer women in providing support by reviewing papers and proposals. Compared to women biologists, physicists, chemists, computer scientists, and electrical engineers report $20 \%, 23 \%, 22 \%$, and $24 \%$ (respectively) fewer women introducing them to potential collaborators outside of the university. Women in physics, chemistry, and EE report women in their networks nominating them for an award or as an invited speaker at significantly lower rates than women in biology. In sum, women in biology report significantly more women in their support networks than women in physics, chemistry, CS, and EE.

For women scientists, age and marital and parental status are not significantly related to having women in the support network. Citizenship is positively related to increases in the number of women introducing them to collaborators outside the university and nominating them for awards. Women US citizens report $26 \%$ more women in their networks introducing them to collaborators as compared to those who are not US citizens. Because successful scientists have strong department ties and multiple bridging ties (outside the department) (Etzkowitz 2000), it is important to note that women providing introductions to individuals outside of the university indicates women playing an important role in helping colleagues build bridging ties. US citizens also report 33\% more women nominating them for awards or inviting them as a guest speaker, as compared to non-US citizens. Women scientists who are not US citizens are significantly less connected to women networks and possibly less connected than their US counterparts.

In summary, we find overwhelming support for our first and second hypotheses that the presence of women in scientists' advice and support networks vary by sex. Women scientists report significantly more women in their networks. For example, women as compared to men in the STEM fields highlighted in this study have, on average, $18 \%$ more women in their support networks and $15 \%$ more women in their advice networks. The variation of women in women's networks is significantly related to field of science, citizenship, and in some cases time since PhD and rank. Meanwhile, variation in the presence of women in 
men's networks is largely related to field of science, time since $\mathrm{PhD}$, and family structure (e.g. married and having kids).

We find mixed support for hypotheses three and four, which expect that scientists will receive different types of support and advice from women in their networks. For men scientists, assistant professors report significantly less women in their informal networks providing advice about publishing and grant getting, but more likely to have women in the network that provide advice about careers, colleagues, an work/family balance. Among women scientists, we do not see consistent patterns for turning to women for particular types of advice or support, though we do find that women assistant professors are significantly less likely that full professors to have women in the networks reviewing their papers. Women are more likely to have women "friends" in their grant, career, and colleague advice networks whereas men are more likely to have women in the colleague and work/family balance advice networks.

Finally, we find strong support for the fifth hypothesis; scientists’ patterns for advice seeking and support from women colleagues vary significantly by field. Overall, as compared to biologists, men and women physicists are the least likely to have women in their advice and support networks. In fact, in comparison to all the fields of science in this study, the physicists report the lowest proportion of women in their networks. There are significant differences across all types of advice and support networks and field of science.

\section{Discussion and Conclusions}

The presence of women in science networks represents not only the integration of women in the field but diverse networks. Of particular importance to this research is the presence of women in both women's and men's networks. If women are equally present in men and women's networks, then women are achieving a stronger more integrated presence across the field. If women are not present, or only present in other women's networks, then we are seeing an advancement of women in isolated communities. The analysis presented in this paper elucidates the challenges of critical mass and isolation. What happens when policy efforts increase the production of women scientists and advancement of women scientists in academia, but those women remain in a separate and, doubtfully, equal system? An increase of women in STEM fields may simply result in a separate community of scientists - a women’s community. 
We propose that an increase of women in women and men's informal networks signifies an integration of women into the networks of all scientists. Not only would this mean that women scientists are indeed advancing in the field and achieving a breakthrough in informal advice and support networks, but also that men and women alike are developing more diverse networks which signal a maturity of contacts and access to social capital that is more expansive as compared to less diverse networks.

Overall, the results of the present analysis indicate that field of science is a critical, significant predictor of the proportion of women in scientists' informal networks. There are a number of possible explanations for these results. First, and most obvious, in fields where there are few women (e.g. physics) there are simply fewer women available to be a part of informal networks. Second, because women make up a larger proportion of junior scientists, it may be that scientists are turning to senior faculty for advice and support and of course it is more likely that a senior scientist is a man. While both of these explanations are plausible and probable, it also occurs to us that these explanations do not explain the simple fact that women make up a larger proportion of women's networks than men's networks. Thus, even if women only make up four to six percent of the senior faculty in top physical science departments (Handelsman et al. 2005, pg. 1190), women still manage to have on average twice as many women in their networks as do men, pointing to a continued imbalance of the penetration of women into scientific advice and support networks. A third explanation for the variation of women's penetration of informal networks by field of science, might be drawn from Kretschmer and Kretschmer (2007) which find that co-authorship relationships can be categorized as two types: "Birds of a feather flock together" and "Opposites attract". They find scientists operate in an open, flexible culture that enables individual scientists to seek out similar or dissimilar collaborators, based on time, culture, and other conditions (e.g. field of science, rank). In sum, variations in co-authorship collaboration and the prevalence of homophily or heterophily, might be explained by field of science, changes in the nature of research in those fields, the structure of work (e.g. labs or physical proximity), or sub-domains of research within disciplines (Kretschmer and Kretschmer 2007; Pepe and Rodriguez 2009).

Interestingly, we see that rank is not a consistent significant predictor of having women in advice and support networks. Etzkowitz and colleagues (2000) hypothesize that because junior men have grown up in a generation with a higher expectation for balanced household responsibilities, they might be more 
likely to work with senior and junior women. They argue that "[y]ounger male faculty members express an understanding and interest in building more productive cross-gender and gender-inclusive networks, yet new strategies are needed and other problems exist” (Etzkowitz et al. 2000: 177). Our results indicate some support for Etzkowitz and colleagues' hypothesis that young men are more "relational" and working with more women in their networks, as compared to senior men or other junior women. We find that men assistant and associate professors, compared to full professors, report around 2\% more women in their informal networks. Specifically men assistant and associate professors turn to women in their informal networks for advice about careers and colleagues, but not publishing and grant getting advice, and they report support from women who review their papers and introduce them to potential collaborators. This research indicates that science and informal networks are changing - for both men and women scientists. Our future research will hope to untangle the possible generational differences and the ways in which junior men and women may seek support from one another or senior men and women.

Finally, one of the most interesting findings of the analysis is the significant relationship between being a woman non-US citizen and having women in advice and support networks. For men, citizenship is related to the presence of women in career and work/family advice networks. In comparison, women US citizens are significantly more likely than non-citizens to have women in all of their informal networks. Etzkowitz and colleagues (2000) hypothesize that although a critical minority (15\%) can advance the group's interests this critical minority can be subdivided and weak when split by nationality. When studying co-authorship patterns, Pepe and Rodriquez (2009) notes that scientists might have strong preferences for collaborating with others from their country of origin, even when working in the US. It is possible that women non-US citizens are isolated from informal networks. It is also possible that they are simply drawing from informal networks abroad. Although this research did not set out to test a hypothesis about the isolation of minorities, we find significant differences between women scientists who are US citizens and non-citizens.

We expect that the difference between women in advice and support networks by citizenship is probably driven by a number of factors, including the number of women citizens and noncitizens in each field, cultural differences between US and non-US natives, and opportunities that are limited to US citizens. First, the basic numbers issue. In this sample, $20 \%$ of all respondents are not US citizens and $17 \%$ 
of the women respondents are not US citizens. Non-US citizens make up between 6\% (EAS) and 34\% (electrical engineering) of the women respondents (see table 1). It follows that in some fields, women nonUS citizens might be significantly isolated from their colleagues and women colleagues in particular.

The second possible explanation for these findings is the cultural differences between US- and non-US citizens. It is possible that non-citizen, women scientists have larger and different family burdens and thus smaller informal professional networks. It may also be possible that women non-US citizens seek out relationships with more powerful men scientists as a means to advancing their careers or that they are seeking advice and support from scientists in their country of origin. While these explanations are plausible, it is important to note that there are fewer significant differences in the presence of women in the advice and support networks of men US citizens and men non-US citizens. Thus, there is something interesting going on within the advice and support networks of women non-US citizens that warrants further investigation.

The third possible explanation for the differences between women US and non-US citizens' networks is that women US citizens have benefited from the widespread implementation of federal, state, and institutional policies to advance women in science. While these efforts to support women scientists (e.g. research funding, networking support, and specialized professional opportunities) are commendable, many of them are limited to US citizens. For example, we see that women US citizens, as compared to women non-citizens, report having 33\% more women in their networks nominating them for awards or invited speaking opportunities. It is possible that these awards are limited to US citizens or that the introductions and nominations are occurring through relationships developed through professional networking events or other opportunities sponsoring US women. While the current analysis presents no direct evidence to support a hypothesis that US citizens benefit more than non-citizens from institutionalized efforts aimed at advancing women scientists, we believe this is an important avenue for future research. As non-citizens begin to make up a larger portion of the women scientists in US academic institutions, it will be increasingly important to understand how the presence of women in scientists' advice and support networks is shaped by citizenship status.

While this research offers only a small glimpse into the patterns of scientists' informal networks, it raises important questions for future research. This research offers some understanding of the ways in 
which women and men rely on women scientists for advice and support. We hope that further analysis will enable us to understand the relationships between seeking advice and support from women scientists and seniority, how sex balance networks are related to productivity, and how efforts to increase the presence of women in science may differently affect outcomes for women US citizens compared to non-US citizens. Because "[o]ne of the underlying barriers to the success of women scientists is the structure of their social networks” (Etzkowitz et al. 2000, pg. 176), these questions remain vitally important to understanding the ways in which policy can best affect the outcomes of women in science and thus, outcomes for all scientists. 
Table 1 Summary statistics

\begin{tabular}{|c|c|c|c|c|c|}
\hline Variables & Valid & Min & Max & Mean & $\begin{array}{l}\text { Std. } \\
\text { Dev. }\end{array}$ \\
\hline \multicolumn{6}{|l|}{ Women in Network } \\
\hline Women in Network (\%) & 1494 & .00 & 1.00 & .14 & .17 \\
\hline \multicolumn{6}{|l|}{ Women Advice Seeking (\%) } \\
\hline Publishing & 852 & .00 & 1.00 & .13 & .27 \\
\hline Grant getting & 1015 & .00 & 1.00 & .13 & .26 \\
\hline Career development & 1067 & .00 & 1.00 & .14 & .26 \\
\hline Interaction with colleagues & 1157 & .00 & 1.00 & .13 & .25 \\
\hline Work/family balance & 695 & .00 & 1.00 & .22 & .35 \\
\hline Total Advice (5) & 1307 & .00 & 1.00 & .13 & .23 \\
\hline \multicolumn{6}{|l|}{ Women Support Giving (\%) } \\
\hline Reviewing papers or proposals & 529 & .00 & 1.00 & .12 & .27 \\
\hline Introducing to potential collaborators & 517 & .00 & 1.00 & .11 & .27 \\
\hline Nominating for award & 492 & .00 & 1.00 & .09 & .25 \\
\hline Total Support (3) & 864 & .00 & 1.00 & .10 & .24 \\
\hline \multicolumn{6}{|l|}{ Position } \\
\hline Assistant Professor & 1494 & 0 & 1 & .22 & .41 \\
\hline Associate Professor & 1494 & 0 & 1 & .24 & .43 \\
\hline Full Professor & 1494 & 0 & 1 & .54 & .50 \\
\hline \multicolumn{6}{|l|}{ Field } \\
\hline Biology & 1494 & 0 & 1 & .22 & .42 \\
\hline Chemistry & 1494 & 0 & 1 & .17 & .37 \\
\hline Computer Sciences & 1494 & 0 & 1 & .14 & .35 \\
\hline Earth and Atmospheric Sciences & 1494 & 0 & 1 & .13 & .34 \\
\hline Electrical Engineering & 1494 & 0 & 1 & .13 & .34 \\
\hline Physics & 1494 & 0 & 1 & .21 & .40 \\
\hline \multicolumn{6}{|l|}{ Demographic } \\
\hline Woman & 1494 & 0 & 1 & 0.14 & 0.34 \\
\hline Age & 1474 & 28 & 82 & 49.78 & 10.47 \\
\hline Age Squared & 1474 & 784 & 6724 & 2587.28 & 1071.12 \\
\hline Time Since $\mathrm{PhD}$ & 1489 & 1 & 54 & 20.53 & 11.06 \\
\hline Tenured & 1487 & 0 & 1 & .76 & .43 \\
\hline White & 1494 & 0 & 1 & .79 & .41 \\
\hline Citizen & 1485 & 0 & 1 & .81 & .40 \\
\hline Married & 1479 & 0 & 1 & .89 & .32 \\
\hline Dependent Children & 1040 & 0 & 1 & .52 & .50 \\
\hline Married with Kids & 1170 & 0 & 1 & .45 & .50 \\
\hline \multicolumn{6}{|l|}{ Others } \\
\hline Friends (\%) & 1494 & .00 & 1.00 & .22 & .27 \\
\hline \multicolumn{6}{|l|}{$\mathrm{N}=1494$} \\
\hline Women Citizenship & & $\begin{array}{c}\text { US } \\
\text { citizen }\end{array}$ & & & \\
\hline Biology & & $86 \%$ & & & \\
\hline Chemistry & & $83 \%$ & & & \\
\hline Computer Sciences & & $79 \%$ & & & \\
\hline Earth and Atmospheric Sciences & & $93 \%$ & & & \\
\hline Electrical Engineering & & $63 \%$ & & & \\
\hline Physics & & $71 \%$ & & & \\
\hline
\end{tabular}


Table 2 Presence of women in science networks, by field, academic position and respondent sex

\begin{tabular}{lccc}
\hline \multicolumn{1}{c}{ Characteristics } & \multicolumn{3}{c}{$\begin{array}{c}\text { Percentage of respondents that have } \\
\text { at least one woman in their network }\end{array}$} \\
\cline { 2 - 4 } & Men & Women & Total \\
\hline Total Sample & $55 \%$ & $80 \%$ & $58 \%$ \\
Field & & & \\
$\quad$ Biology & $64 \%$ & $85 \%$ & $68 \%$ \\
$\quad$ Chemistry & $62 \%$ & $74 \%$ & $64 \%$ \\
$\quad$ Computer Sciences & $50 \%$ & $72 \%$ & $53 \%$ \\
Earth \& Atmospheric Sciences & $69 \%$ & $89 \%$ & $73 \%$ \\
$\quad$ Electrical Engineering & $47 \%$ & $70 \%$ & $48 \%$ \\
$\quad$ Physics & $41 \%$ & $73 \%$ & $44 \%$ \\
Position & & & \\
$\quad$ Assistant Professor & $55 \%$ & $79 \%$ & $60 \%$ \\
$\quad$ Associate Professor & $60 \%$ & $80 \%$ & $63 \%$ \\
Full Professor & $53 \%$ & $80 \%$ & $55 \%$ \\
\hline
\end{tabular}


Table 3 Average percent of women’s advice and support networks

\begin{tabular}{lrrr}
\hline \multirow{2}{*}{ Women in Network } & Average \% & Average $\%$ & Average $\%$ \\
\cline { 4 - 4 } & & Women & Men \\
\hline Advice Seeking & & & \\
Publishing & $13 \%$ & $23 \%$ & $11 \%$ \\
Grant getting & $13 \%$ & $23 \%$ & $11 \%$ \\
Career development & $14 \%$ & $27 \%$ & $11 \%$ \\
Interaction with colleagues & $13 \%$ & $27 \%$ & $11 \%$ \\
Work/family balance & $22 \%$ & $46 \%$ & $16 \%$ \\
Total Advice (5) & $13 \%$ & $27 \%$ & $10 \%$ \\
Support Giving & & & \\
Reviewing papers or proposals & $12 \%$ & $26 \%$ & $9 \%$ \\
Introducing to potential collaborators & $11 \%$ & $28 \%$ & $7 \%$ \\
$\quad$ Nominating for award & $9 \%$ & $29 \%$ & $5 \%$ \\
Total Support (3) & $10 \%$ & $27 \%$ & $7 \%$ \\
\hline
\end{tabular}


Table 4 Models predicting the proportion of women in scientists' networks, total advice networks, and total support networks (full sample, men, women)

\begin{tabular}{|c|c|c|c|c|c|c|c|c|c|}
\hline \multirow[b]{3}{*}{ Variables } & \multicolumn{3}{|c|}{ Full Sample } & \multicolumn{3}{|c|}{ Men Only } & \multicolumn{3}{|c|}{ Women Only } \\
\hline & $\begin{array}{c}\text { Women in } \\
\text { Network }\end{array}$ & $\begin{array}{l}\text { Women in } \\
\text { Advice } \\
\text { Network } \\
\end{array}$ & $\begin{array}{c}\text { Women in } \\
\text { Support } \\
\text { Network } \\
\end{array}$ & $\begin{array}{c}\text { Women } \\
\text { in } \\
\text { Network }\end{array}$ & $\begin{array}{c}\text { Women in } \\
\text { Advice } \\
\text { Network }\end{array}$ & $\begin{array}{c}\text { Women in } \\
\text { Support } \\
\text { Network } \\
\end{array}$ & $\begin{array}{c}\begin{array}{c}\text { Women } \\
\text { in } \\
\text { Network }\end{array} \\
\end{array}$ & $\begin{array}{l}\text { Women in } \\
\text { Advice } \\
\text { Network } \\
\end{array}$ & $\begin{array}{c}\text { Women in } \\
\text { Support } \\
\text { Network }\end{array}$ \\
\hline & B & B & B & B & B & B & B & B & B \\
\hline (Constant) & $0.072 * * *$ & -0.010 & 0.276 & $0.117^{* *}$ & 0.111 & $0.450 * * *$ & 0.092 & -0.110 & 0.050 \\
\hline Assistant $\mathrm{t}^{\mathrm{a}}$ & $0.022 * * *$ & $0.024^{* *}$ & 0.022 & $0.023 * * *$ & 0.015 & $0.030^{* *}$ & 0.008 & 0.061 & -0.007 \\
\hline Associate & $0.025^{* * *}$ & $0.014^{*}$ & $0.021^{*}$ & $0.021 * * *$ & 0.002 & 0.002 & $0.045^{* *}$ & $0.080 * * *$ & $0.108^{* *}$ \\
\hline Women & $0.118 * * *$ & $0.146 * * *$ & $0.180^{* * *}$ & & & & & & \\
\hline Physics $^{\mathrm{b}}$ & $-0.099 * * *$ & $-0.117 * * *$ & $-0.095^{* * *}$ & $-0.095 * * *$ & $-0.109 * * *$ & $-0.077 * * *$ & $-0.115^{* * *}$ & $-0.173 * * *$ & $-0.171^{* * *}$ \\
\hline Chemistry & $-0.043^{* * *}$ & $-0.074 * * *$ & $-0.041^{* * *}$ & $-0.037 * * *$ & $-0.076^{* * *}$ & $-0.040 * * *$ & $-0.083^{* * *}$ & $-0.074 * *$ & -0.050 \\
\hline EAS & $-0.018^{* * *}$ & $-0.019^{*}$ & $0.041^{* * *}$ & -0.007 & -0.004 & $0.068^{* * *}$ & $-0.075^{* * *}$ & $-0.096 * * *$ & -0.056 \\
\hline Computer Science & $-0.033 * * *$ & -0.011 & -0.010 & $-0.028 * * *$ & -0.001 & 0.003 & $-0.059 * * *$ & $-0.080 * *$ & $-0.089^{*}$ \\
\hline Electrical Eng. & $-0.071 * * *$ & $-0.083^{* * *}$ & $-0.069 * * *$ & $-0.062 * * *$ & $-0.073 * * *$ & $-0.051 * * *$ & $-0.132 * * *$ & $-0.127 * * *$ & $-0.128 *$ \\
\hline Time Since PhD & $0.003 * * *$ & $0.005^{* * *}$ & $0.003^{* *}$ & $0.004 * * *$ & $0.007 * * *$ & $0.005^{* * *}$ & $-0.00 *$ & -0.005 & $-0.010^{*}$ \\
\hline Age & $0.001 * * *$ & 0.006 & -0.006 & 0.001 & 0.003 & $-0.012 * * *$ & 0.001 & 0.008 & 0.003 \\
\hline Age Squared & $0.000 * * *$ & $0.000 * * *$ & 0.000 & $0.000 *$ & $0.000 * * *$ & 0.000 & 0.000 & 0.000 & 0.000 \\
\hline White & $0.025^{* * *}$ & $0.023 * * *$ & -0.013 & $0.027 * * *$ & $0.034 * * *$ & 0.008 & 0.020 & -0.028 & $-0.083^{*}$ \\
\hline Citizen & $0.020 * * *$ & $0.027 * * *$ & $0.025^{* *}$ & $0.014^{* *}$ & $0.015^{*}$ & 0.008 & $0.050^{* *}$ & $0.098 * * *$ & $0.112^{* *}$ \\
\hline Married & $-0.018 * * *$ & $-0.022 *$ & 0.004 & $-0.046 * * *$ & $-0.049 * * *$ & -0.013 & $0.038 *$ & 0.033 & 0.052 \\
\hline Dependent children & $-0.065^{* *}$ & $-0.054^{* *}$ & $-0.074 * *$ & $-0.100 * * *$ & $-0.053^{*}$ & $-0.083 * *$ & 0.016 & -0.048 & -0.012 \\
\hline Married w/ kids & $0.057^{* *}$ & $0.051^{*}$ & $0.061^{*}$ & $0.093^{* * *}$ & $0.049 *$ & $0.071^{* *}$ & -0.025 & 0.040 & -0.037 \\
\hline \%friends in network & $0.070 * * *$ & $0.058^{* * *}$ & -0.006 & $0.060 * * *$ & $0.047 * * *$ & -0.012 & $0.197 * * *$ & $0.239 * * *$ & $0.217^{* * *}$ \\
\hline $\mathrm{N}$ & 1012 & 887 & 576 & 561 & 4866 & 305 & 451 & 401 & 271 \\
\hline $\mathrm{R}^{2}$ & 0.159 & 0.121 & 0.129 & 0.096 & 0.067 & 0.071 & 0.167 & 0.135 & 0.111 \\
\hline Adjusted $\mathrm{R}^{2}$ & 0.157 & 0.118 & 0.124 & 0.094 & 0.064 & 0.066 & 0.151 & 0.116 & 0.083 \\
\hline
\end{tabular}

Reference Categories: ${ }^{\mathrm{a}}$ Full Professor; ${ }^{\mathrm{b}}$ Biology 
Table 5A Models predicting the proportion of women in men scientists' advice networks

\section{MEN}

(Constant)

Assistant $^{\mathrm{a}}$

Associate

Physics $^{\mathrm{b}}$

Chemistry

Earth and Atmospheric Sciences

Computer Science

Electrical Engineering

Time Since PhD

Age

Age Squared

White

Citizen

Married

Has dependent children

Married w/ kids (interaction)

Percent of "friends" in network

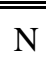

$\mathrm{R}^{2}$

Adjusted R2

\begin{tabular}{|c|c|c|c|c|c|c|c|c|c|}
\hline \multicolumn{2}{|c|}{$\begin{array}{c}\text { Publishing } \\
\text { Advice }\end{array}$} & \multicolumn{2}{|c|}{ Grant Advice } & \multicolumn{2}{|c|}{$\begin{array}{l}\text { Career } \\
\text { Advice }\end{array}$} & \multicolumn{2}{|c|}{$\begin{array}{c}\text { Colleague } \\
\text { Advice } \\
\end{array}$} & \multicolumn{2}{|c|}{$\begin{array}{c}\text { Work/Family } \\
\text { Advice } \\
\end{array}$} \\
\hline $\mathrm{B}$ & Sig & $\mathrm{B}$ & Sig & $\mathrm{B}$ & Sig & $\mathrm{B}$ & Sig & $\mathrm{B}$ & Sig \\
\hline 0.236 & & 0.127 & & 0.117 & & 0.275 & $* * *$ & 0.384 & $*$ \\
\hline-0.053 & $* * *$ & -0.036 & $* *$ & 0.038 & $* *$ & 0.029 & $* *$ & 0.008 & \\
\hline-0.062 & $* * *$ & -0.011 & & 0.026 & $* *$ & 0.017 & $*$ & -0.030 & \\
\hline-0.117 & $* * *$ & -0.117 & $* * *$ & -0.130 & $* * *$ & -0.108 & $* * *$ & -0.089 & $* * *$ \\
\hline-0.029 & * & -0.044 & $* * *$ & -0.109 & $* * *$ & -0.095 & $* * *$ & -0.009 & \\
\hline-0.032 & $* *$ & -0.044 & $* * *$ & 0.007 & & -0.009 & & 0.139 & $* * *$ \\
\hline 0.003 & & -0.007 & & 0.036 & $* * *$ & -0.024 & $* *$ & -0.074 & $* * *$ \\
\hline-0.073 & $* * *$ & -0.079 & $* * *$ & -0.057 & $* * *$ & -0.105 & $* * *$ & 0.042 & $*$ \\
\hline 0.003 & $* *$ & 0.004 & $* * *$ & 0.010 & $* * *$ & 0.007 & $* * *$ & 0.002 & \\
\hline 0.001 & & 0.003 & & 0.005 & & -0.003 & & -0.013 & \\
\hline 0.000 & & 0.000 & $* *$ & 0.000 & $* * *$ & 0.000 & & 0.000 & \\
\hline 0.021 & & 0.044 & $* * *$ & -0.011 & & 0.032 & $* * *$ & 0.004 & \\
\hline 0.027 & $*$ & -0.006 & & 0.034 & $* * *$ & 0.005 & & 0.062 & $* * *$ \\
\hline-0.101 & $* * *$ & 0.013 & & -0.079 & $* * *$ & -0.046 & $* * *$ & -0.049 & \\
\hline-0.081 & $*$ & -0.055 & & -0.049 & & -0.029 & & -0.155 & $* *$ \\
\hline 0.079 & $*$ & 0.034 & & 0.036 & & 0.037 & & 0.194 & $* * *$ \\
\hline 0.016 & & -0.021 & & -0.004 & & 0.035 & $* * *$ & 0.096 & $* * *$ \\
\hline 301 & & 354 & & 377 & & 423 & & 236 & \\
\hline 0.045 & & 0.052 & & 0.081 & & 0.070 & & 0.074 & \\
\hline 0.040 & & 0.047 & & 0.076 & & 0.066 & & 0.067 & \\
\hline
\end{tabular}

*** $\mathrm{p}<.01$; ** $\mathrm{p}<.05 ;{ }^{*} \mathrm{p}<.10$

Reference Categories: ${ }^{\mathrm{a}}$ Full Professor; ${ }^{\mathrm{b}}$ Biology 
Table 5B Models predicting the proportion of women in women scientists' advice networks

\begin{tabular}{|c|c|c|c|c|c|c|c|c|c|c|}
\hline \multirow[t]{2}{*}{ WOMEN } & \multicolumn{2}{|c|}{$\begin{array}{c}\text { Publishing } \\
\text { Advice }\end{array}$} & \multicolumn{2}{|c|}{$\begin{array}{l}\text { Grant } \\
\text { Advice }\end{array}$} & \multicolumn{2}{|c|}{$\begin{array}{l}\text { Career } \\
\text { Advice } \\
\end{array}$} & \multicolumn{2}{|c|}{$\begin{array}{c}\text { Colleague } \\
\text { Advice }\end{array}$} & \multicolumn{2}{|c|}{$\begin{array}{c}\text { Work/Family } \\
\text { Advice } \\
\end{array}$} \\
\hline & B & Sig & B & Sig & B & Sig & B & Sig & B & Sig \\
\hline (Constant) & 0.744 & $*$ & -0.731 & $* *$ & 0.039 & & 0.375 & & 0.022 & \\
\hline Assistant $^{\mathrm{a}}$ & 0.015 & & 0.094 & $*$ & 0.012 & & 0.054 & & 0.031 & \\
\hline Associate & 0.099 & $* *$ & 0.056 & & 0.052 & & 0.052 & & 0.094 & * \\
\hline Physics $^{b}$ & -0.128 & $* * *$ & -0.100 & $* *$ & -0.231 & $* * *$ & -0.154 & $* * *$ & -0.133 & $* *$ \\
\hline Chemistry & -0.125 & $* * *$ & -0.040 & & -0.124 & $* * *$ & -0.049 & & -0.024 & \\
\hline Earth and Atmospheric Sciences & -0.055 & & -0.029 & & -0.170 & $* * *$ & -0.070 & $* *$ & -0.194 & $* * *$ \\
\hline Computer Science & -0.051 & & -0.113 & $* * *$ & -0.131 & $* * *$ & 0.044 & & -0.223 & $* * *$ \\
\hline Electrical Engineering & -0.223 & $* * *$ & -0.133 & $* *$ & -0.159 & $* * *$ & -0.071 & & -0.183 & $* *$ \\
\hline Time Since PhD & 0.004 & & -0.004 & & -0.009 & $* *$ & -0.004 & & -0.018 & $* * *$ \\
\hline Age & -0.022 & & 0.033 & $* *$ & 0.003 & & -0.015 & & 0.011 & \\
\hline Age Squared & 0.000 & & 0.000 & $*$ & 0.000 & & 0.000 & & 0.000 & \\
\hline White & 0.020 & & -0.032 & & -0.028 & & -0.001 & & -0.071 & \\
\hline Citizen & 0.058 & & 0.100 & $* * *$ & 0.102 & $* * *$ & 0.145 & $* * *$ & 0.186 & $* * *$ \\
\hline Married & 0.045 & & 0.025 & & 0.085 & $* *$ & -0.048 & & -0.017 & \\
\hline Has dependent children & -0.037 & & -0.057 & & -0.017 & & 0.002 & & 0.126 & \\
\hline Married w/ kids (interaction) & 0.017 & & 0.015 & & -0.029 & & 0.057 & & -0.095 & \\
\hline Percent of "friends" in network & 0.094 & & 0.173 & $* * *$ & 0.172 & $* * *$ & 0.167 & $* * *$ & 0.120 & \\
\hline $\mathrm{N}$ & 281 & & 329 & & 347 & & 354 & & 259 & \\
\hline $\mathrm{R}^{2}$ & 0.080 & & 0.089 & & 0.143 & & 0.114 & & 0.116 & \\
\hline Adjusted R2 & 0.052 & & 0.065 & & 0.122 & & 0.091 & & 0.087 & \\
\hline
\end{tabular}

Reference Categories: ${ }^{\mathrm{a}}$ Full Professor; ${ }^{\mathrm{b}}$ Biology 
Table 6 Models predicting the proportion of women in scientists' support networks, by sex

(Constant)

Assistant $^{\mathrm{a}}$

Associate

Physics ${ }^{\mathrm{b}}$

Chemistry

Earth and Atmospheric Sciences

Computer Science

Electrical Engineering

Time Since PhD

Age

Age Squared

White

Citizen

Married

Has dependent children

Married w/ kids (interaction)

Percent of "friends" in network

\begin{tabular}{|c|c|c|c|c|c|c|c|c|c|c|c|}
\hline \multicolumn{6}{|c|}{ MEN } & \multicolumn{6}{|c|}{ WOMEN } \\
\hline \multicolumn{2}{|c|}{ Review } & \multicolumn{2}{|c|}{ Introduce } & \multicolumn{2}{|c|}{ Nominate } & \multicolumn{2}{|c|}{ Review } & \multicolumn{2}{|c|}{ Introduce } & \multicolumn{2}{|c|}{ Nominate } \\
\hline B & Sig & B & Sig & B & Sig & B & Sig & B & Sig & B & Sig \\
\hline 0.384 & $* *$ & 0.049 & & 0.466 & $* * *$ & 0.155 & & 0.419 & & -0.231 & \\
\hline 0.012 & & 0.101 & $* * *$ & -0.028 & & -0.173 & $* *$ & 0.061 & & 0.091 & \\
\hline 0.057 & $* * *$ & 0.013 & & -0.016 & & -0.045 & & 0.156 & $* *$ & 0.042 & \\
\hline-0.115 & $* * *$ & -0.080 & $* * *$ & -0.060 & $* * *$ & -0.269 & $* * *$ & -0.203 & $* * *$ & -0.232 & $* * *$ \\
\hline-0.062 & $* * *$ & 0.010 & & -0.010 & & 0.061 & & -0.228 & $* * *$ & -0.175 & $* *$ \\
\hline-0.002 & & 0.051 & $* * *$ & 0.099 & $* * *$ & -0.069 & & -0.071 & & -0.093 & \\
\hline-0.116 & $* * *$ & -0.011 & & 0.057 & $* * *$ & -0.156 & $* *$ & -0.222 & $* * *$ & -0.025 & \\
\hline-0.112 & $* * *$ & -0.051 & $* * *$ & -0.058 & $* * *$ & -0.051 & & -0.236 & $* * *$ & -0.269 & $* *$ \\
\hline 0.004 & $* *$ & 0.006 & $* * *$ & 0.004 & $* *$ & -0.014 & $* *$ & -0.001 & & -0.015 & $*$ \\
\hline-0.010 & * & 0.005 & & -0.010 & $*$ & 0.010 & & -0.011 & & 0.011 & \\
\hline 0.000 & & 0.000 & * & 0.000 & & 0.000 & & 0.000 & & 0.000 & \\
\hline 0.010 & & -0.012 & & 0.021 & & -0.091 & * & -0.177 & $* * *$ & -0.137 & $* *$ \\
\hline 0.032 & $* *$ & 0.014 & & 0.004 & & 0.052 & & 0.259 & $* * *$ & 0.327 & $* * *$ \\
\hline 0.035 & & -0.014 & & -0.081 & $* * *$ & 0.071 & & -0.085 & & 0.044 & \\
\hline-0.100 & $*$ & -0.110 & $* *$ & -0.127 & $* * *$ & -0.056 & & -0.237 & & -0.073 & \\
\hline 0.061 & & 0.102 & $* *$ & 0.097 & $* *$ & 0.019 & & 0.276 & & 0.076 & \\
\hline 0.015 & & -0.059 & $* * *$ & -0.058 & $* * *$ & 0.059 & & 0.260 & $* * *$ & 0.088 & \\
\hline 176 & & 180 & & 170 & & 176 & & 158 & & 160 & \\
\hline 0.089 & & 0.084 & & 0.092 & & 0.105 & & 0.224 & & 0.157 & \\
\hline 0.080 & & 0.076 & & 0.083 & & 0.064 & & 0.179 & & 0.107 & \\
\hline
\end{tabular}

*** $\mathrm{p}<.01 ; * * \mathrm{p}<.05 ; * \mathrm{p}<.10$

Adjusted $\mathrm{R}^{2} \quad 0.080$

Reference Categories: ${ }^{\mathrm{a}}$ Full Professor; ${ }^{\mathrm{b}}$ Biology

Review: reviewed your papers or proposals prior to submission (on which they were not a co-author)

Introduce: introduced you to potential collaborators outside of your university

Nominate: nominated you for an award or as an invited speaker 


\section{Acknowledgments:}

Data analyzed in this paper were collected under the auspices of the 2005-09 project, "Women in Science and Engineering: Network Access, Participation, and Career Outcomes”, (NETWISE) a project funded by the National Science Foundation (Grant \# REC-0529642; Co-PIs Dr. Julia Melkers and Dr. Eric Welch). All content is the expression of the authors alone and does not represent the views of the NSF or NETWISE principal investigators. All usual disclaimers apply. 


\section{References}

Acker, J. (1990). Hierarchies, Jobs, Bodies: A Theory of Gendered Organizations. Gender and Society, 4(2), 139-158.

Browne, K. R. (2004). Women in the Workplace: Evolutionary Perspectives and Public Policy. In C. Crawford \& C. Salmon (Eds.), Evolutionary Psychology, Public Policy and Personal Decisions. New Haven: Yale University Press.

Callister, R. R. (2006). The impact of gender and department climate on job satisfaction and intentions to quit for faculty in science and engineering fields. Journal of Technology Transfer, 31(3), 367-375.

Chemical Sciences Roundtable. (2003). Minorities in the Chemical Workforce: Diversity Models that Work - A Workshop Report to the Chemical Sciences Roundtable. Washington, DC: National Research Council.

Curtin, J. M., Blake, G., \& Cassagnau, C. (1997). The climate for women graduate students in physics. Journal of Women and Minorities in Science and Engineering, 3, 95-117.

Dresselhaus, M. S., Franz, J. R., \& Clark, B. C. (1994). Interventions to Increase the Participation of Women in Physics. Science, 1392-1393.

Ellemers, N., van den Heuvel, H., de Gilder, D., Maass, A., \& Bonvini, A. (2004). The underrepresentation of women in science: Differential commitment or the queen bee syndrome?. British Journal of Social Psychology, 43, 315-338.

Emmett, A. (1992). A Woman's Institute of Technology. Technology Review, 16-18.

Epstein, C. F. (1970). Woman's Place: Options and Limits in Professional Careers. Berkeley, CA: University of California Press.

Etzkowitz, H., Kemelgor, C., Neuschatz, M., Uzzi, B., \& Alonzo, J. (1994). The paradox of critical mass for women in science. Science, 266, 51-54.

Etzkowitz, H., Kemelgor, C., \& Uzzi, B. (2000). Athena Unbound: The advancement of women in science and technology. Cambridge, UK: Cambridge University Press.

Etzkowitz, H., \& Kemelgor, C. (2001). Gender inequality in science: A universal condition. Minerva, 39, 153-174.

Fox-Keller, E. (1985). Reflections on Gender and Science. New Haven: Yale University Press.

Friedkin, N. E. (1978). University Social-Structure and Social Networks among Scientists. American Journal of Sociology, 83(6), 1444-1465.

Gutek, B. A. (1985). Sex and the Workplace. San Francisco, CA: Jossey Bass.

Handelsman, J., Cantor, N., Carnes, M., Denton, D., Fine, E., Grosz, B., et al. (2005). More Women in Science. Science, 309, 1190-1191.

Horning, B. (1993). The Controversial Career of Evelyn Fox Keller. Technology Review, 58-68.

Kanter, R. M. (1977). Some effects of proportions on group life: Skewed sex ratios and responses to token women. American Journal of Sociology, 82, 965-990.

Kemelgor, C., \& Etzkowitz, H. (2001). Overcoming isolation: Women's dilemmas in American academic science. Minerva, 39(2), 239-257.

Konrad, A. M. (1986). The Impact of Workgroup Composition on Social Integration and Evaluation. Ph.D dissertation, Claremont University, Claremont, CA.

Koshland, D. E. Jr. (1994). Women in Science. Science, 1355.

Kulis, S. (1997). Gender segregation among college and university employees. Sociology of Education, 70(2), 151-173.

Kulis, S., Chong, Y., \& Shaw, H. (1999). Discriminatory organizational contexts and black scientists on postsecondary faculties. Research In Higher Education, 40(2), 115-148.

Kulis, S., \& Sicotte, D. (2002). Women scientists in academia: Geographically constrained to big cities, college clusters, or the coasts?. Research in Higher Education, 43(1), 1-30.

Kulis, S., Sicotte, D., \& Collins, S. (2002). More than a pipeline problem: Labor supply constraints and gender stratification across academic science disciplines. Research in Higher Education, 43(6), 657-691.

Lee, S. (2004). Foreign-born scientists in the United States: Do they perform differently than native-born scientists? Ph.D Dissertation, Georgia Institute of Technology, Atlanta, GA.

Lin, N., Ensel, W. M., \& Vaughn, J. (1981). Social Resources and Strength of Ties: Structural Factors in Occupational Status Attainment. American Sociological Review, 46, 393-405.

Long, J. S. (1992). Measures of sex differences in scientific productivity. Social Forces, 71, 159-178. 
McPherson, M., Smith-Lovin, L., \& Cook, J. M. (2001). Birds of a feather: Homophily in social networks. Annual Review of Sociology, 27, 415-444.

Merton, R. K. (1968). The Matthew Effect in Science. Science, 159, 56-63.

Merton, R. K. (1973). The Sociology of Science: Theoretical and Empirical Investigations. Chicago, IL: University of Chicago Press.

National Academies of Science. (2003). BIO2010: Transforming Undergraduate Education for Future Research Biologists. Washington DC.

National Science Foundation. ADVANCE: Increasing the Participation and Advancement of Women in Academic Science and Engineering Careers. Retrieved January 15, 2009 from http://www.nsf.gov/funding/pgm_summ.jsp?pims_id=5383

National Science Foundation (2004). Division of Science Resources Statistics. Doctoral Scientists and Engineers: 2001 Profile Tables NSF 04-312.

Oliver, P. E., \& Marwell, G. (1988). The Paradox of Group Size in Collective Action: A Theory of the Critical Mass. II. American Sociological Review, 53(1), 1-8.

Rodriguez, M. A., \& Pepe, A. (2008). On the relationship between the structural and socioacademic communities of a coauthorship network. Journal of Informetrics, 2(3), 195-201.

Pepe, Alberto, \& Marko A. Rodriguez. (2009). Collaboration in sensor network research: an in-depth longitudinal analysis of assortative mixing patterns. Scientometrics. Published online 31 December 2009. DOI 10.1007/s11192-009-0147-2

Powell, W. W., Koput, K. W. \& Smith-Doerr, L. (1996). Interorganizational Collaboration and the Locus of Innovation: Networks of Learning in Biotechnology. Administrative Science Quarterly, 41, 116-145.

Rapoport, R., Bailyn, L., Fletcher, J.K., \& Pruitt, B.H. (2002). Beyond Work-Family Balance: Advancing Gender Equity and Workplace Performance. San Francisco, CA: Jossey-Bass.

Rosenfeld, R. (1984). Academic Career Mobility for Psychologists. In Haas,Violet \& C. Perrucci (Eds.), Women in Scientific and Engineering Professions. Ann Arbor: University of Michigan Press.

Sabharwal, M. (2008). Examining the Job Satisfaction Patterns of Foreign-born Scientists and Engineers in the Academy: A Comparison with U.S. born Faculty. Paper presented at the Thirtieth Annual APPAM Research Conference.

Settles, I. H., Cortina, L.M., Stewart, A.J. \& Malley, J. (2007). Voice matters: Buffering the impact of a negative climate for women in science. Psychology of Women Quarterly, 31, 270-281.

Seymour, E. (1995). The Loss of Women from Science, Mathematics and Engineering Undergraduate Majors: An Explanatory Account. Science Education, 34, 110-131.

Sonnert, G. (1995). What makes a good scientist? Determinants of peer evaluation among biologists. Social Studies of Science, 25, 35-55.

Sonnert, G., \& Holton, G. (1996). Career patterns of women and men in sciences. American Scientist, 84(1), 63-69.

South, S. J., Bonjean, C. M., Markjam, W. T., \& Corder, J. (1982). Social Structure and Intergroup Interaction. American Sociological Review, 47, 687-599.

Tierney, W. G., Bensimon, E.M. (1996). Promotion and Tenure: Community and socialization in academe. Albany, NY: SUNY Press.

Tierney, W. G., Rhoads, R.A. (1993). Enhancing promotion, tenure and beyond: Faculty socialization as a cultural process. ASHE-ERIC Higher Education Report No.6: 63-72, Washington, DC: George Washington University.

Toren, N., \& Kraus, V. (1987). The Effects of Minority Size on Women's Position in Academia. Social Forces, 65(4), 1090-1100.

Valian, V. (2005). Beyond gender schemas: Improving the advancement of women in academia. Hypatia, 20(3), 198-213.

Zuckerman, H. (1989). Accumulation of advantage and disadvantage: The theory and its intellectual biography. In C. M. S. Tabboni (Eds.), L'Opera di R. K. Merton e la Sociologia Contemporeana. Genoa: Edizioni Culturali Internationali Genova. 
Appendix I

Correlation Table

\begin{tabular}{|c|c|c|c|c|c|c|c|c|c|c|c|c|c|c|c|c|c|c|c|}
\hline & Assist & & Assoc & & Full & & Woman & & $\mathrm{BIO}$ & & $\mathrm{CHEM}$ & & CS & & EAS & & EE & & PHYS \\
\hline Woman & 0.029 & & -0.026 & & -0.003 & & & & & & & & & & & & & & \\
\hline Biology & -0.011 & & -0.006 & & 0.014 & & -0.008 & & & & & & & & & & & & \\
\hline Chemistry & 0.020 & & -0.007 & & -0.011 & & 0.030 & & -0.217 & ** & & & & & & & & & \\
\hline Computer Science & 0.001 & & -0.004 & & 0.003 & & -0.009 & & -0.201 & ** & -0.203 & ** & & & & & & & \\
\hline Earth and Atmospheric Sciences & -0.027 & & -0.015 & & 0.038 & & 0.020 & & -0.224 & ** & -0.226 & ** & -0.210 & *夫 & & & & & \\
\hline Eectrical Engineering & 0.005 & & 0.051 & * & -0.051 & * & -0.021 & & -0.178 & ** & -0.180 & ** & -0.167 & ** & -0.186 & *夫 & & & \\
\hline Physics & 0.013 & & -0.013 & & 0.000 & & -0.016 & & -0.207 & ** & -0.209 & ** & -0.194 & *夫 & -0.216 & *夫 & -0.172 & ** & \\
\hline Age & -0.603 & ** & -0.110 & ** & 0.634 & ** & -0.083 & ** & 0.113 & *夫 & -0.046 & & -0.001 & & 0.042 & & -0.119 & *夫 & -0.005 \\
\hline Tenured & -0.888 & *夫 & 0.227 & ** & 0.580 & ** & -0.050 & & 0.043 & & -0.011 & & 0.012 & & -0.004 & & -0.007 & & -0.034 \\
\hline Time since PhD & -0.621 & ** & -0.144 & ** & 0.681 & *夫 & -0.091 & ** & 0.103 & ** & 0.011 & & -0.056 & * & 0.015 & & -0.125 & ** & 0.036 \\
\hline White, not Hispanic & -0.115 & $\star \star$ & -0.007 & & 0.108 & ** & 0.036 & & 0.064 & * & 0.064 & * & -0.075 & *夫 & 0.135 & ** & -0.182 & $\star \star$ & -0.037 \\
\hline Citizen & -0.324 & ** & 0.005 & & 0.283 & ** & 0.066 & * & 0.093 & ** & -0.005 & & -0.043 & & 0.093 & ** & -0.123 & ** & -0.035 \\
\hline Married & -0.053 & * & -0.003 & & 0.050 & & -0.165 & ** & -0.009 & & -0.041 & & 0.029 & & -0.006 & & 0.023 & & 0.009 \\
\hline Dependent Children & 0.072 & * & 0.117 & ** & -0.168 & ** & 0.072 & * & -0.043 & & 0.009 & & -0.042 & & -0.006 & & 0.081 & $\star \star$ & 0.008 \\
\hline Percent of "friends" in network & -0.041 & & 0.029 & & 0.010 & & -0.005 & & 0.071 & $\star \star$ & 0.012 & & -0.034 & & 0.074 & ** & -0.118 & $\star \star$ & -0.024 \\
\hline
\end{tabular}

**. Pearson Correlation is significant at the 0.01 level (2-tailed); *. Pearson Correlation is significant at the 0.05 level (2-tailed).

\begin{tabular}{|c|c|c|c|c|c|c|c|c|c|c|c|c|c|}
\hline & Age & & Tenured & & $\begin{array}{c}\text { since } \\
\text { PhD }\end{array}$ & & White & & Citizen & & Married & & Kids \\
\hline Tenured & 0.594 & ** & & & & & & & & & & & \\
\hline Time since PhD & 0.938 & *夫 & 0.608 & ** & & & & & & & & & \\
\hline White, not Hispanic & 0.149 & ** & 0.108 & ** & 0.163 & ** & & & & & & & \\
\hline Citizen & 0.342 & ** & 0.331 & ** & 0.338 & ** & 0.300 & ** & & & & & \\
\hline Married & 0.051 & & 0.056 & * & 0.056 & * & 0.039 & & 0.067 & * & & & \\
\hline Dependent Children & -0.323 & ** & -0.094 & ** & -0.317 & ** & -0.051 & & -0.030 & & 0.206 & ** & \\
\hline Percent of "friends" in network & 0.009 & & 0.037 & & 0.024 & & 0.084 & ** & 0.111 & $\star \star$ & 0.055 & * & 0.016 \\
\hline
\end{tabular}

**. Pearson Correlation is significant at the 0.01 level (2-tailed); *. Pearson Correlation is significant at the 0.05 level (2-tailed). 